DIMENSI, VOL. 6, NO. $3: 349-361$

NOVEMBER 2017

ISSN: 2085-9996

\title{
ESTIMASIVALUE AT RISK DENGANGENERALIZED STUDENT-T DISTRIBUTION UNTUK MEMPREDIKSI RETURN INVESTASI
}

\section{ESTIMATED OF VALUE AT RISK WITH GENERALIZED STUDENT-T DISTRIBUTION TO PREDICT INVESTMENT RETURN}

\author{
Hermansah $^{1}$, Yudhi Hanggara ${ }^{2}$ \\ ${ }^{1,2}$ (Pendidikan Matematika FKIP Universitas Riau Kepulauan Batam) \\ 'bankhermansah@gmail.com, ${ }^{2}$ yudhihanggara@gmail.com
}

\begin{abstract}
Abstrak
Dalam artikel ini dijelaskan tentang estimasi kerugian Value at Risk menggunakan Generalized Student-t Distribution untuk return aset tunggal. Generalized Student-t Distribution merupakan perluasan dari distribusi normal standar dan chi square dsitribution. Generalized Student-t Distribution memiliki sifat yang thin tailed dan simetris. Sehingga estimasi Value at Risk dengan pendekatan Generalized Student-t Distribution diharapkan dapat memberikan estimasi kerugian yang baik untuk data yang memiliki sifat thin tailed dan simetris.
\end{abstract}

Kata kunci:Return, Value at Risk dan Distribusi Student-t.

\section{Abstract}

In this article we explain about estimation of Value at Risk using Generalized Student-t Distribution for single asset return. The Generalized Student-t Distribution is an extension of the standard normal distribution and chi square dsitribution. Generalized Student-t Distribution has thin tailed and symmetrical properties. So the Value at Risk estimation with the Generalized Student-t Distribution approach is expected to provide good loss estimation for data that has thin tailed and symmetrical properties.

Keywords:Return, Value at Risk and Student-t Distribution.

\section{PENDAHULUAN}

Pasar modal adalah pertemuan antar pihak yang memiliki kelebihan dana dengan pihak yang membutuhkan dana dengan cara memperjualbelikan sekuritas (Hartono, 2008). Pasar modal menjalankan dua fungsi, yaitu sebagai sarana bagi perusahaan untuk mendapatkan dana dari investor dan sebagai sarana bagi investor untuk berinvestasi. Investasi adalah penundaan 
konsumsi sekarang untuk digunakan didalam produksi yang efisien selama periode waktu tertentu. Bentuk yang paling umum dalam investasi pasar modal adalah saham. Saham merupakan bukti pemilikan sebagian dari perusahaan. Dalam investasi saham, investor mengharapkan tingkat return yang tinggi, maka investor harus berani menanggung risiko yang tinggi pula (Rosadi, 2009).

Nilai risiko dapat diukur dengan beberapa cara, diantaranya adalah Value at Risk (VaR). VaR merupakan nilai estimasi besarnya kerugian maksimal yang mungkin terjadi pada periode tertentu dengan tingkat keyakinan tertentu dan dalam kondisi pasar yang normal. VaR memberikan informasi tentang besarnya kerugian, periode waktu dan tingkat keyakinan (Dowd, 2002).

Generalized Student-t Distributionmemiliki sifat thin tailed dan simetris. Generalized Student-t distribution memberikan variasi dalam memodelkan ukuran risiko pasar dengan Value at Risk. Dengan demikian, diharapkan estimasi ukuran risiko dapat disesuaikan dengan model data return yang beragam, sehingga diperoleh keakuratan perhitungan estimasi yang lebih baik. Estimasi Value at Riskdengan pendekatan Generalized Student- $t$ Distributiondiharapkan dapat memberikan estimasi kerugian yang baik untuk data yang memiliki sifat thin tailed dan simetris (Hermansah, 2014, 2015, 2017).

\section{METODOLOGI}

\section{Return}

Investor berinvestasi untuk mendapatkan tingkat pengembalian, yakni hasil yang diperoleh dalam berinvestasi. Terdapat dua jenis tingkat pengembalian yaitu tingkat pengembalian yang diharapkan (expected return) dan realisasi tingkat pengembalian (realized return). Expected return adalah tingkat pengembalian yang diharapkan akan diperoleh investor di waktu mendatang. Realized return adalah tingkat pengembalian yang telah terjadi, dihitung berdasarkan data historis. Tingkat pengembalian jenis ini penting karena dapat digunakan sebagai salah satu parameter kinerja perusahaan. Tingkat pengembalian ini juga berguna sebagai dasar perhitungan expected return(Rosadi, 2011). 
Realisasi tingkat pengembalian terbagi atas beberapa macam. Menurut kegunaannya, realisasi tingkat pengembalian yang sering digunakan, yaitu:

1. Profit/loss (P/L)

Profit/loss merupakan perhitungan return yang sederhana. Profit/loss didefinisikan sebagai nilai dari aset atau portofolio pada saat $t$ dikurangi dengan nilai aset pada saat $t-1$. Secara matematis, dapat dituliskan

$P / L_{t}=P_{t}-P_{t-1}$.

Jika nilai $P / L_{t}$ positif, maka dapat dikatakan mendapatkan keuntungan, sedangkan jika nilai $P / L_{t}$ negatif, maka mengalami kerugian.

2. Loss/profit (L/P)

Loss/profit merupakan negatif dari $P / L_{t}$. Dalam model matematis dapat dituliskan $L / P_{t}=-\left(P / L_{t}\right)$.

3. Return Total (Simple Net Return)

Return total merupakan tingkat pengembalian keseluruhan dari investasi dalam suatu periode tertentu. Return total (Rt) pada sekuritas antara periode $t-1$ sampai dengan periode ke $t$ didefinisikan sebagai berikut.

$R_{t}=\frac{P_{t}-P_{t-1}}{P_{t-1}}=\frac{P_{t}}{P_{t-1}}-1$,

dengan $P_{t}$ adalah harga sekuritas pada harga ke-t dan $P_{t-1}$ adalah harga sekuritas pada harga ke $t-1$.

4. Return Relatif (Simple Gross Return)

Return total dapat bernilai positif dan negatif. Pada return relatif dirumuskan sebagai $1+R_{t}$, sehingga returnrelatif nilainya selalu positif.

5. Log Return (Continuously Compounded Return)

Nilai logaritma dari simple gross return disebut log return, yakni 
$r_{t}=\ln \left(1+R_{t}\right)=\ln \frac{P_{t}}{P_{t-1}}=\ln P_{t}-\ln P_{t-1}$ Selanjutnya, dapat didefinisikan log returnk-periode sebagai

$$
\begin{aligned}
& r_{t}[k]=\ln \left(1+R_{t}[k]\right) \\
& =\ln \left(\left(1+R_{t}\right) .\left(1+R_{t-1}\right) \ldots\left(1+R_{t-k+1}\right)\right) \\
& =\ln \left(1+R_{t}\right)+\ln \left(1+R_{t-1}\right) \ldots\left(\ln 1+R_{t-k+1}\right)=\sum_{j=0}^{k-1} r_{t-j} .
\end{aligned}
$$

Terlihat bahwa return $r_{t}$ dalam k-periode merupakan jumlahan dari return $r_{t}$ dalam 1 periode yang berhubungan. Hasil ini lebih cocok dengan sifat yang diinginkan mengenai return, yakni sebagai contoh, jika indeks $t$ menyatakan periode waktu harian, maka nilai return $k$-hari merupakan jumlahan dari returnk-hari yang bersesuaian. Karena sifat ini, dalam praktik bentuk ini return $r_{t}$ sering digunakan dibandingkan dengan $R_{t}$.

\section{Risiko}

Risiko merupakan kata yang sudah didengar setiap hari. Biasanya kata tersebut mempunyai konotasi yang negatif, sesuatu yang tidak disukai, sesuatu yang ingin dihindari. Menurut Bank Indonesia, risiko adalah potensi terjadinya peristiwa yang dapat menimbulkan kerugian(Hanafi, 2006).

Risiko dibedakan menurut jenis-jenisnya.

1. Risiko kredit, yaitu risiko yang disebabkan oleh counterparty (debitur) dalam melaksanakan kewajiban-kewajibannya sesuai yang disyaratkan oleh kontrak/perjanjian.

2. Risiko negara dan pengalihan, yaitu risiko yang disebabkan oleh kondisi lingkungan ekonomi, sosial, politik dari negara asal counterparty.

3. Risiko pasar, yaitu risiko yang disebabkan oleh pergerakan harga pasar.

4. Risiko tingkat bunga, yaitu risiko yang disebabkan oleh pergerakan tingkat bunga di pasar.

5. Risiko likuiditas, yaitu risiko yang disebabkan oleh ketidakmampuan bank untuk mengakomodasi berkurangnya pasiva atau untuk membiayai peningkatan di sisi aktiva atau aset. 
6. Risiko operasional, yaitu risiko yang disebabkan oleh pelanggaran atas ketentuanketentuan internal maupun atas kebijakan-kebijakan bank.

7. Risiko hukum, yaitu risiko yang disebabkan oleh ketidakcukupan atau kesalahan dalam pemberian pendapat hukum maupun dokumentasi hukum.

8. Risiko reputasi, yaitu risiko yang disebabkan oleh kegagalan di dalam operasional bank khususnya kegagalan dalam memenuhi ketentuan-ketentuan hukum atau peraturan yang dikenakan atas bank.

\section{Distribusi Normal}

Distribusi normal cukup populer dan banyak digunakan dalam memodelkan data. Bentuk distribusi normal sebagai kurva adalah seperti lonceng yang simetris(Bain \& Engelhardt, 1991). Suatu variabel random $X$ mengikuti distribusi normal dengan mean $\mu$ dan variansi $\sigma^{2}$, dituliskan $X \square N\left(\mu, \sigma^{2}\right)$, jika mempunyai fungsi densitas $f\left(x ; \mu, \sigma^{2}\right)=\frac{1}{\sqrt{2 \pi} \sigma} e^{-\frac{1}{2}\left(\frac{x-\mu}{\sigma}\right)^{2}} ;-\infty<x<\infty ;-\infty<\mu<\infty ; 0<\sigma<\infty$.

Dengan mensubstitusikan $z=\frac{x-\mu}{\sigma}$ ke persamaan di atas diperoleh distribusi normal standar dengan fungsi densitas

$$
f(z)=\frac{1}{\sqrt{2 \pi}} e^{\frac{z^{2}}{2}} ;-\infty<z<\infty .
$$

Jika Z memiliki fungsi densitas $f(z)=\frac{1}{\sqrt{2 \pi}} e^{\frac{z^{2}}{2}}$, maka $Z \square N(0,1)$.

\section{Distribusi Gamma}

Definisi fungsi gamma (Asimow \& Maxwel, 2010)adalah

$$
\Gamma(\alpha)=\int_{0}^{\infty} x^{\alpha-1} e^{-x} d x ; 0<\alpha<\infty .
$$

\section{Teorema:}

1. $\Gamma(\alpha)=(\alpha-1) \Gamma(\alpha-1) ; \quad \alpha>1$. 
Hermansah Dan Yudhi Hanggara; Estimasivalue At Risk Dengangeneralized Student-T...

2. Jika $\alpha=n$ dengan $n$ bilangan bulat positif maka $\Gamma(n)=(n-1)$ !.

3. $\Gamma\left(\frac{1}{2}\right)=\sqrt{\pi}$.

Bukti:

1. Tulis $u=x^{\alpha-1}$ dan $d v=e^{-x} d x$.

Sehingga diperoleh $d u=(\alpha-1) x^{\alpha-2} d x$ dan $v=-e^{-x}$.

Jadi

$$
\begin{aligned}
& \Gamma(\alpha)=\int_{0}^{\infty} x^{\alpha-1} e^{-x} d x \\
& =-\left.x^{\alpha-1} e^{-x}\right|_{x=0} ^{\infty}+(\alpha-1) \int_{0}^{\infty} x^{\alpha-2} e^{-x} d x \\
& =-(0-0)++(\alpha-1) \int_{0}^{\infty} x^{(\alpha-1)-1} e^{-x} d x \\
& =(\alpha-1) \Gamma(\alpha-1) .
\end{aligned}
$$

2. Menggunakan sifat (1) diperoleh

$$
\begin{aligned}
& \Gamma(1)=\int_{0}^{\infty} e^{-x} d x=1=0 ! \\
& \Gamma(2)=(2-1) \Gamma(2-1)=(1) \Gamma(1)=(1) 0 !=1 ! \\
& \Gamma(3)=(3-1) \Gamma(3-1)=(2) \Gamma(2)=(2) 1 !=2 ! \\
& \Gamma(4)=(4-1) \Gamma(4-1)=(3) \Gamma(3)=(3) 2 !=3 !
\end{aligned}
$$

Sehingga analog untuk $n$ bilangan bulat positif diperoleh

$\Gamma(n)=(n-1)$ !.

3. Tulis $x=\frac{u^{2}}{2}$.

Sehingga diperoleh $d x=u . d u$. 
Jadi

$$
\begin{aligned}
& \Gamma\left(\frac{1}{2}\right)=\int_{0}^{\infty} x^{-\frac{1}{2}} e^{-x} d x \\
& =\int_{0}^{\infty}\left(\left(\frac{u^{2}}{2}\right)^{-\frac{1}{2}} e^{-\frac{u^{2}}{2}} u\right) d u \\
& =\sqrt{2} \int_{0}^{\infty} e^{-\frac{u^{2}}{2}} d u \\
& =\sqrt{2}\left(\frac{1}{2} \sqrt{2 \pi}\right) \\
& =\sqrt{\pi} .
\end{aligned}
$$

Variabel random non negatif $X$ dikatakan berdistribusi gamma, dinotasikan $X \square \Gamma(\alpha, \beta)$, jika $X$ memiliki fungsi densitas yang berbentuk

$$
f(x ; \alpha, \beta)=\frac{1}{\beta^{\alpha} \Gamma(\alpha)} x^{\alpha-1} e^{-\frac{x}{\beta}} ; 0 \leq x \leq \infty, \alpha>0 .
$$

\section{Distribusi Chi Square}

Jika variabel random $X=Z_{1}^{2}+Z_{2}^{2}+\ldots+Z_{n}^{2}$ dengan $\left(Z_{i}\right)_{i=1}^{n}$ adalah variabel random normal standar yang saling independen, maka $X \square \Gamma\left(\frac{n}{2}, \frac{1}{2}\right)$. Distribusi ini disebut distribusi chi square berderajat bebas $\mathrm{n}$ (Asimow \& Maxwel, 2010), dinotasikan $X \square \chi^{2}(n)$. Jika $X \square \chi^{2}(n)$, maka memiliki fungsi densitas sebagai

$$
f(x)=\frac{1}{2^{\frac{n}{2}} \Gamma\left(\frac{n}{2}\right)} x^{\frac{n}{2}-1} e^{-\frac{x}{2}} ; x \geq 0, n \geq 0 .
$$

\section{Fungsi Beta}

Definisi fungsi beta (Asimow \& Maxwel, 2010)adalah

$$
B(\alpha, \beta)=\int_{0}^{1} x^{\alpha-1}(1-x)^{\beta-1} d x ; \alpha>0, \beta>0 .
$$

Fungsi beta dapat juga dituliskan sebagai 
$B(\alpha, \beta)=\frac{\Gamma(\alpha) \Gamma(\beta)}{\Gamma(\alpha+\beta)}$.

Sedangkan definisi dari fungsi beta tak lengkap adalah

$I_{x}(\alpha, \beta)=\frac{B_{x}(\alpha, \beta)}{B(\alpha, \beta)}=\frac{1}{B(\alpha, \beta)} \int_{0}^{x} t^{\alpha-1}(1-t)^{\beta-1} d t ;$

$0<x<1, \alpha>0, \beta>0$.

\section{Distribusi Student-t}

Dipunyai $Z$ dan $X$ variabel random yang independen dengan $Z$ berdistribusi normal standar dan $X$ berdistribusi chi square dengan derajat bebas v. Jika $t(v)$ transformasi dari $Z$ dan $X$ berbentuk $t(v)=\frac{Z}{\sqrt{X / v}}$ dengan fungsi densitas

$f_{t}(t)=\frac{\Gamma\left(\frac{v+1}{2}\right)}{\sqrt{\pi \nu} \Gamma\left(\frac{v}{2}\right)}\left(\frac{1}{1+\frac{t^{2}}{v}}\right)^{\frac{v+1}{2}},-\infty<t<\infty$,

maka $t$ dikatakan distribusi student-t dengan derajat bebas v(Asimow \& Maxwel, 2010).

Fungsi distribusi dari student-t adalah

$F_{t}(t)=\left\{\begin{array}{c}\frac{1}{2}-\frac{1}{2} I_{\frac{t^{2}}{v+t^{2}}}\left(\frac{1}{2}, \frac{v}{2}\right) \text { untuk }-\infty<t<0 \\ \frac{1}{2}+\frac{1}{2} I_{\frac{t^{2}}{v+t^{2}}}\left(\frac{1}{2}, \frac{v}{2}\right) \text { untuk } 0<t<\infty\end{array}\right.$,

Dimana $I_{\frac{t^{2}}{v+t^{2}}}\left(\frac{1}{2}, \frac{v}{2}\right)$ merupakan fungsi beta tak lengkap.

Bukti:

$F(t)=\int_{-t}^{t} f(u) d u$ 


$$
\begin{aligned}
& =\int_{-t}^{t} \frac{1}{\sqrt{\pi v}} \frac{\Gamma\left(\frac{v+1}{2}\right)}{\Gamma\left(\frac{v}{2}\right)}\left(1+\frac{u^{2}}{v}\right)^{-\frac{(v+1)}{2}} d u \\
& =\frac{1}{\sqrt{\pi v}} \frac{\Gamma\left(\frac{v+1}{2}\right)}{\Gamma\left(\frac{v}{2}\right)} \int_{-t}^{t}\left(1+\frac{u^{2}}{v}\right)^{-\frac{(v+1)}{2}} d u \\
& =\frac{1}{\sqrt{v}} \frac{\Gamma\left(\frac{v+1}{2}\right)}{\Gamma\left(\frac{1}{2}\right) \Gamma\left(\frac{v}{2}\right)^{t}} \int_{-t}^{t}\left(1+\frac{u^{2}}{v}\right)^{-\frac{(v+1)}{2}} d u \\
& =\frac{1}{\sqrt{v} B\left(\frac{v}{2}, \frac{1}{2}\right)^{-t}} \int^{t}\left(1+\frac{u^{2}}{v}\right)^{-\frac{(v+1)}{2}} d u \\
& =\frac{2}{\sqrt{v} B\left(\frac{v}{2}, \frac{1}{2}\right)_{0}^{t}} \int_{0}\left(1+\frac{u^{2}}{v}\right)^{-\frac{(v+1)}{2}} d u .
\end{aligned}
$$

Misal

$$
x=\frac{v}{v+u^{2}},
$$

maka

$$
\begin{aligned}
& u^{2}=\frac{v}{x}-v \\
& u=\left(\frac{v}{x}-v\right)^{\frac{1}{2}} \\
& d u=\frac{1}{2}\left(\frac{v}{x}-v\right)^{-\frac{1}{2}}\left(-\frac{v}{x^{2}}\right) d x=-\frac{v}{2 x^{2}}\left(\frac{v}{x}-v\right)^{-\frac{1}{2}} d x .
\end{aligned}
$$

Batas bawah jika $u=0$ maka $x=1$. 
Hermansah Dan Yudhi Hanggara; Estimasivalue At Risk Dengangeneralized Student-T...

Batas atas jika $u=t$ maka $x=\frac{v}{v+t^{2}}$.

Sehingga

$$
\begin{aligned}
& F_{t}(t)=\frac{2}{\sqrt{v} B\left(\frac{v}{2}, \frac{1}{2}\right)} \int_{1}^{\frac{v}{v+t^{2}}}\left(1+\frac{\frac{v}{x}-v}{v}\right)^{-\frac{(v+1)}{2}}\left(-\frac{v}{2 x^{2}}\left(\frac{v}{x}-v\right)^{-\frac{1}{2}}\right) d x \\
& =\frac{-2 v}{2 \sqrt{v} B\left(\frac{v}{2}, \frac{1}{2}\right)} \int_{1}^{\frac{v}{v+t^{2}}}\left(\frac{v+\frac{v}{x}-v}{v}\right)^{-\frac{(v+1)}{2}} \frac{1}{x^{2}} \frac{(v-v x)^{-\frac{1}{2}}}{x^{-\frac{1}{2}}} d x \\
& =\frac{-v^{\frac{1}{2}}}{B\left(\frac{v}{2}, \frac{1}{2}\right)} \int_{1}^{\frac{v}{v+t^{2}}}\left(\frac{1}{x}\right)^{-\frac{(v+1)}{2}} \frac{1}{x^{2}} \frac{x^{\frac{1}{2}}}{v^{\frac{1}{2}}(1-x)^{\frac{1}{2}}} d x \\
& =\frac{1}{B\left(\frac{v}{2}, \frac{1}{2}\right)} \int_{\frac{v}{v+t^{2}}}^{1} x^{\frac{(v+1)}{2}} \frac{x^{-2} x^{\frac{1}{2}}}{(1-x)^{\frac{1}{2}}} d x \\
& =\frac{1}{B\left(\frac{v}{2}, \frac{1}{2}\right)} \int_{\frac{v}{v+t^{2}}}^{1} x^{\frac{v}{2}-1}(1-x)^{-\frac{1}{2}} d x \\
& =\frac{1}{B\left(\frac{v}{2}, \frac{1}{2}\right)} \int_{\frac{v}{v+t^{2}}}^{1} x^{\frac{v}{2}-1}(1-x)^{\frac{1}{2}-1} d x \\
& =\frac{1}{B\left(\frac{v}{2}, \frac{1}{2}\right)}\left[\int_{0}^{1} x^{\frac{v}{2}-1}(1-x)^{\frac{1}{2}-1} d x-\int_{0}^{\frac{v}{v+t^{2}}} x^{\frac{v}{2}-1}(1-x)^{\frac{1}{2}-1} d x\right] \\
& =\frac{1}{B\left(\frac{v}{2}, \frac{1}{2}\right)}\left[B\left(\frac{v}{2}, \frac{1}{2}\right)-B_{\frac{v}{v+t^{2}}}\left(\frac{v}{2}, \frac{1}{2}\right)\right]
\end{aligned}
$$




$$
\begin{aligned}
& =1-\frac{B_{\frac{v}{v+t^{2}}}\left(\frac{v}{2}, \frac{1}{2}\right)}{B\left(\frac{v}{2}, \frac{1}{2}\right)} \\
& =1-I_{\frac{v}{v+t^{2}}}\left(\frac{v}{2}, \frac{1}{2}\right) \\
& =I_{1-\frac{v}{v+t^{2}}}\left(\frac{1}{2}, \frac{v}{2}\right) \\
& =I_{\frac{t^{2}}{v+t^{2}}}\left(\frac{1}{2}, \frac{v}{2}\right) .
\end{aligned}
$$

Diketahui bahwa $F_{t}(t)=\int_{-\infty}^{\infty} f(u) d u=1$ dan distribusi student-t simetrik di $t=0$, maka

$$
F_{t}(t)=\int_{-\infty}^{0} f_{t}(t) d t=\int_{0}^{\infty} f_{t}(t) d t=\frac{1}{2}
$$

Jadi diperoleh

$$
F_{t}(t)=\left\{\begin{array}{l}
\frac{1}{2}-\frac{1}{2} I_{\frac{t^{2}}{v+t^{2}}}\left(\frac{1}{2}, \frac{v}{2}\right),-\infty<t<0 \\
\frac{1}{2}+\frac{1}{2} I_{\frac{t^{2}}{v+t^{2}}}\left(\frac{1}{2}, \frac{v}{2}\right), 0 \leq t<\infty
\end{array} .\right.
$$

\section{PEMBAHASAN}

\section{VaRGeneralized Student-t Distribution}

Value at Risk (VaR) didefinisikan sebagai nilai estimasi besarnya kerugian maksimal yang mungkin terjadi pada periode tertentu dengan tingkat keyakinan tertentu dan dalam kondisi pasar yang normal. Dari definisi tersebut, terdapat tiga variabel yang penting, yakni besarnya kerugian, periode waktu dan tingkat keyakinan.

Secara matematis, $\mathrm{VaR}$ dengan tingkat keyakinan $\alpha$, dinotasikan $\Phi(\alpha)$, dinyatakan sebagai bentuk kuantil ke $(1-\alpha)$ dari distribusi return. Jika dituliskan $f(r(t))$ sebagai fungsi 
densitas peluang dari $r(t)$ dan $F(r(t))$ sebagai fungsi distribusi kumulatifnya, maka secara sederhana dapat dinyatakan $\mathrm{VaR}$ dari $r(t)$ pada tingkat keyakinan $\alpha$ sebagai $F(\Phi)=(1-\alpha)$

Bentuk invers dari fungsi tersebut untuk menghitung nilai VaR, $\Phi=F^{-1}(1-\alpha)$.

Dalam hal ini, VaR merupakan bentuk invers dari fungsi distribusi kumulatif.

Sedangkan perhitungan VaR untuk return berdistribusi student-t diperoleh dengan menggunakan generalized student-t dsitribution. Dengan generalized student- $t$ distribution dimana mean $\mu$, variansi $\sigma^{2}\left(\frac{v}{v-2}\right)$, skew bernilai 0, dan kurtosis $\frac{3(v-2)}{v-4}$, maka kuantil dari generalized student-t distribution adalah $\mu+\sigma \sqrt{\frac{v}{v-2}} t_{\alpha, v}$, dengan $t_{\alpha, v}$ adalah kuantil dari distribusi student-t awal untuk derajat bebas $v$ dan tingkat keyakinan sebesar $\alpha$. Sehingga diperoleh rumus VaR untuk distribusi student-t adalah $V a R=\mu+\sigma \sqrt{\frac{v}{v-2}} t_{\alpha, v}($ Dowd, 2005).

Dalam hal ini, estimasi VaR distribusi student-t menggunakan tingkat keyakinan 95\%,95,5\%, 96\%, 96,5\%,97\%, 97,5\%,98\%, 98,5\%,99\%dan 99,5\%. Adapun hasil estimasi VaRdistribusi student-t yang diperoleh adalah sebagai berikut. Kerugian maksimal untuk investasi sebesar Rp 1 dengan tingkat keyakinan 95\% adalah sebesar Rp 1,645dan kerugian maksimal untuk investasi sebesar Rp 1 dengan tingkat keyakinan 95,5\% adalah sebesar Rp 1,6954.Kerugian maksimal untuk investasi sebesar Rp 1 dengan tingkat keyakinan 96\% adalah sebesar Rp 1,7507dan kerugian maksimal untuk investasi sebesar Rp 1 dengan tingkat keyakinan 96,5\% adalah sebesar Rp 1,8119.Kerugian maksimal untuk investasi sebesar Rp 1 dengan tingkat keyakinan 97\% adalah sebesar Rp 1,8808dan kerugian maksimal untuk investasi sebesar Rp 1 dengan tingkat keyakinan 97,5\% adalah sebesar Rp 1,96.Selanjutnya kerugian maksimal untuk investasi sebesar Rp 1 dengan tingkat keyakinan 98\% adalah sebesar Rp 2,0537 dan kerugian maksimal untuk investasi sebesar Rp 1 dengan tingkat keyakinan 98,5\% adalah sebesar Rp 2,1701. Kemudiankerugian maksimal untuk investasi sebesar Rp 1 
dengan tingkat keyakinan 99\% adalah sebesar Rp 2,3263dan kerugian maksimal untuk investasi sebesar Rp 1 dengan tingkat keyakinan 99,5\% adalah sebesar Rp 2,5758.

\section{KESIMPULAN DAN SARAN}

\section{Kesimpulan}

Dari hasil pembahasanini dapat diambil kesimpulan sebagai berikut:

1. Estimasi nilai Value at Riskmerupakan bentuk invers dari fungsi distribusi kumulatif.

2. Value at Risk cukup baik digunakan karena mengakomodasi bentuk distribusi data return yang memiliki ekor tipis (thin tail) dan simetris.

\section{Saran}

Adapun saran-saran yang dapat disampaikan adalah sebagai berikut:

1. Adanya kesulitan dalam mendapatkan data yang bersifat distribusi student-t.

2. Model estimasi nilai Value at Riskyang dibahas dapat dilanjutkan dengan distribusi data yang lain.

\section{REFERENSI}

Asimow, L. A. \& Maxwell, M. M. 2010. Probability and Statistics with Applications: A Problem Solving Text. Actex Publication: Winsted.

Bain, J. L. \& Engelhard, M, 1991. Introduction to Probability and Mathematical Statistics, Second Edition. Duxbury Prss: California.

Dowd, K.(2002).An introduction to market risk measurement. John Wiley and Sons, Ltd: Chicester.

Dowd, K.(2005).Measuring market risk, second edition. John Wiley and Sons, Ltd: Chicester.

Hanafi, M.M.(2006).Manajemen risiko. UPP STIM YKPN: Yogyakarta.

Hartono, J.(2008).Teori portofolio dan analisis investasi. BPFE: Yogyakarta.

Hermansah. (2014). Estimasi Nilai Risiko kasus Heteroskedastik dengan Generalized Pareto Distribution untuk memprediksi Return Investasi. Prosiding Seminar Nasional Matematika UNUD. Denpasar, Universitas Udayana. 
Hermansah Dan Yudhi Hanggara; Estimasivalue At Risk Dengangeneralized Student-T...

Hermansah. (2015). Estimasi Value at Risk dan Expected Tail Loss kasus Heteroskedastik dengan Generalized Extreme Value untuk Memprediksi Return Investasi. Prosiding SENDIKMAD. Yogyakarta, Universitas Ahmad Dahlan.

Hermansah. (2017). Estimasi Value at Risk denganDistribusiNormaluntuk Memprediksi Return Investasi. Jurnal Mercumatika. Yogyakarta, Universitas Mercu Buana.

Rosadi, D.(2009).Diktat kuliah manajemen risiko kuantitatif. UGM: Yogyakarta.

Rosadi, D. (2011).Diktat kuliah pengantar analisa runtun waktu. UGM: Yogyakarta. 